\title{
Enhancement of solubility BCS class II and IV pharmaceuticals by liqusolid technique: A review
}

\author{
Dwi Retno Sari ${ }^{1, *}$, Yoga Windhu Wardhana ${ }^{2}$, Taofik Rusdiana ${ }^{2}$ \\ ${ }^{1}$ Master Program of Pharmacy, Faculty of Pharmacy, Universitas Padjadjaran, Sumedang, West \\ Java, Indonesia, 45363 \\ ${ }^{2}$ Department of Pharmaceutics and Pharmaceutical Technology, Faculty of Pharmacy, Universitas \\ Padjadjaran, Sumedang, West Java, Indonesia, 45363
}

Received : 18 May 2020/Revised : 23 May 2020/Accepted : 10 Jun 2020/Published : 23 Jun 2020

\begin{abstract}
Many techniques can be used to improve drug solubility, which is the development of the liquisolid technique. This technique has a mechanism for increasing the surface area of the drug as well as wetting from the addition of non-volatile solvents resulting in a lower surface tension and contact angle, so the solubility and drug release very increases. Liquisolid tablets show a lower contact angle compared to the conventional tablets. The liquisolid technique approach is also promising because the process is simple in making low production costs and allows the manufacturing industry, including non-volatile solvents, fillers, dryers, and disintegrants. Liquisolid characterized by specific instruments such as powder X-ray diffraction (PXRD), Fourier transforms infrared spectroscopy (FTIR), differential scanning calorimetry (DSC), and scanning electron microscope (SEM). Several liquisolid techniques are described in this review. The liquisolid technique is proven and able to change the physicochemical properties of active pharmaceutical ingredients, especially the solubility, drug release, and stability of the formula so that this technique can be a solution for class II and IV BCS pharmaceutical active drug classes.
\end{abstract}

Keywords: Active Pharmaceutical Ingredients, Contact Angle, Solubility, Drug Release, Stability, Liquisolid Technique.

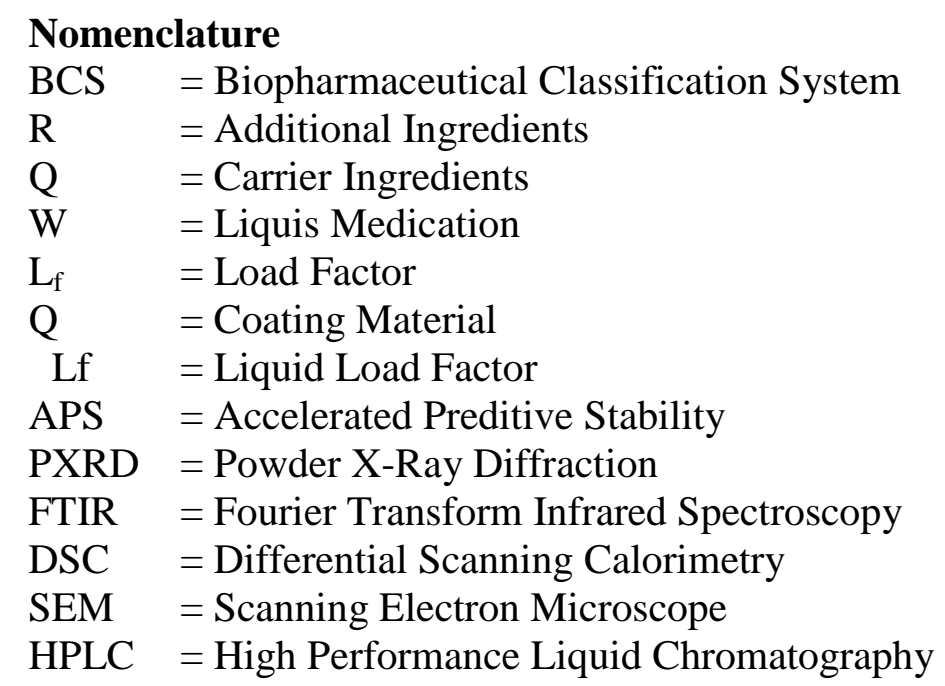




\section{Introduction}

The administration of drugs through the most common and convenient oral route preparations, so that the market is most desirable and many pharmaceutical products are circulating on oral route preparations, except for the oral route preparation the characteristics of active ingredients are required which have adequate solubility and permeability (1). These characteristics are influenced by $\mathrm{pH}$, particle size, surface properties, polarity, $\log \mathrm{P}$, and $\mathrm{D}$ (coefficient distribution) $(2,3)$, so there is something new to increase the solubility of active ingredients, among others, namely: solid dispersion (4), nanoparticle technology (5), cocrystals (6), and micronization (7). Each of the above methods has the disadvantage that there will be a phase separation in the product (into a crystalline form) during the storage process so that it can result in a decrease in solubility and dissolution (solid dispersion) $(8,9)$. The agglomeration force of the micro size hydrophobic drug becomes ineffective, especially when the drug is formulated in a tablet or encapsulate (micronization) (7).

The method of increasing solubility applies to class II BCS (low solubility, high permeability) and class IV (low solubility, low permeability), drugs that have low solubility have a negative effect that is low absorption, the effectiveness of the drug decreases and the dose needed will also increase (10). One of the technological challenges for increasing solubility and improving permeability, especially in class IV BCS, one of the simple methods and sophisticated strategies to improve solubility developed by Spireas (2002), namely the liquisolid technique.

The liquisolid technique is used to increase the solubility of active ingredients. It is carried out with non-volatile solvents into a mass of suspension and converted into an easy-flowing powder so that it can be applied to class II and IV BCS (11). The purpose of this review is to gather information about the liquisolid technique as a solubility enhancer in class II and class IV BCS.

\section{Methodology}

The journals used in this review are from international and national journals. The search strategy is used directly to search for journals online. Journal search websites such as ScienceDirect, NCBI, PubMed, and Researchgate using the keyword "Liquisolid." A review of the liquisolid technique international and national journals from the past eighteen years (2002-2019).

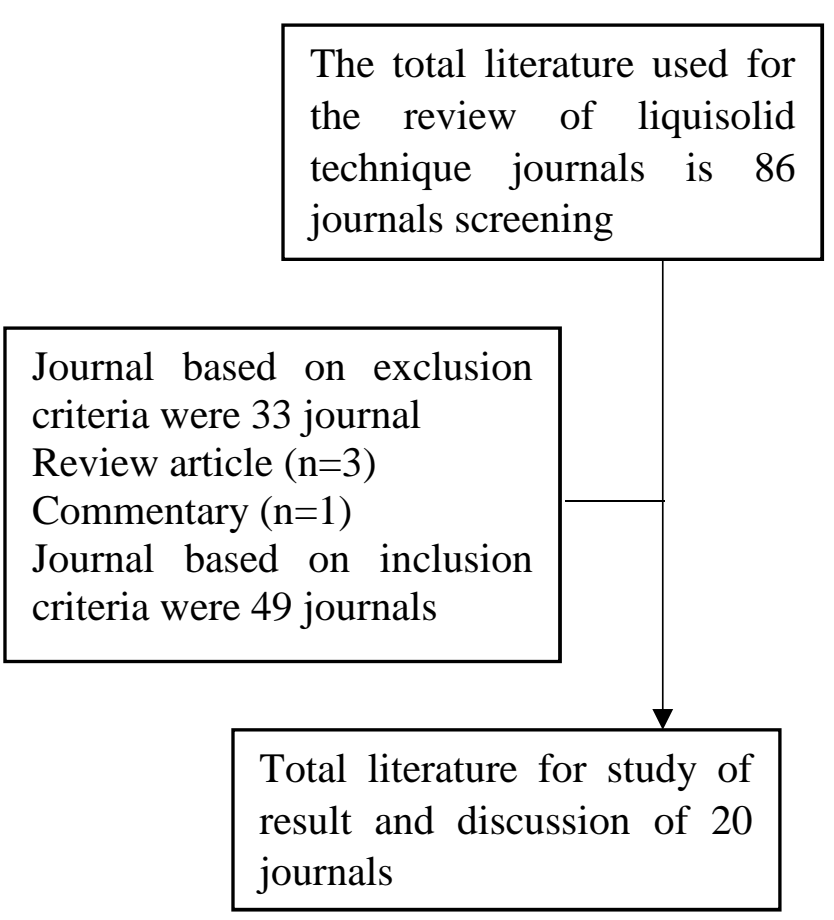

\section{Discussion}

\subsection{Definition of Liquisolid Technique}

The liquisolid technique consists of non-volatile solvents, which can be liquid drug solvents; the drug suspension enters into a porous carrier material. After the carrier is saturated with liquid, the layer is formed on the surface of the particles, which are directly absorbed by the fine particles and appear to look dry (12). So that drug release can be optimized and allow the absorption of drugs to be increased in the digestive tract, and thus, oral bioavailability becomes higher $(13,14)$. In addition to an increase in drug release, the liquisolid approach is also promising because the process is simple in making low production costs, and allows the manufacturing industry to use the liquisolid technique (15). 
This technique is needed first to calculate the amount of material needed, such as a powder filler (carrier and coating material), a mathematical approach is needed for the formulation of the liquisolid system that has been developed (12). This calculation depends on the ratio of the additional material $(\mathrm{R})$ to the liquisolid technique that can be achieved if the addition of carrier fluid is not excessive. The ratio between the liquid medication $(\mathrm{W})$ and carrier material $(\mathrm{Q})$ is known as the liquid load factor (Lf).

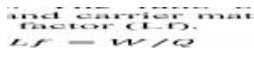

Equation 1

$\mathrm{R}$ is the ratio between the weight of the carrier material $(\mathrm{Q})$ and the coating material $(\mathrm{q})$ in the formula
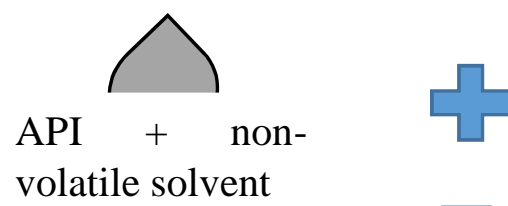

volatile solvent

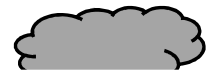

Carrier

Equation 3

With the desired amount of liquid, the amount of carrier and coating material can be calculated if the liquid loading factor is known (12).

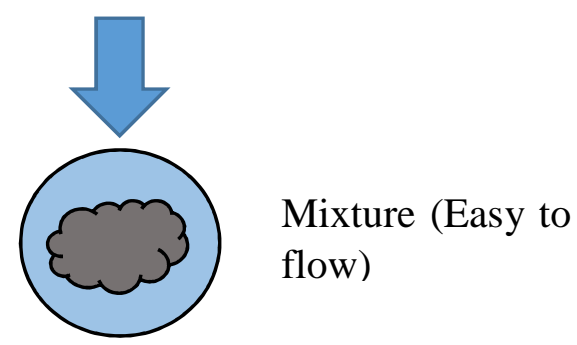

Adsorbent
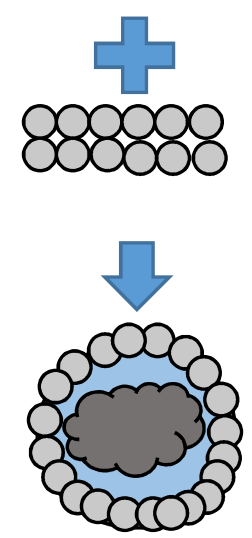

Adsorbent will adsorb the solvent content from the mixture

Figure 1. The core is involved in the development of the liquisolid technique (16).

\section{Mechanism of Increasing Drug Release in the Liquisolid Technique}

1. There is an increase in the surface area of the drug when the medicinal material is in the mass of liquisolid (Suspension) and is completely dissolved in a non-volatile solvent and will be in a state of molecular dispersion in the powder mixture. It causes the surface area of the medicinal material to be released to be increased (12). 
2. There is an increase in drug solubility in the water when non-volatile solvents are used on the solid or liquid interface of a liquisolid particle and dissolution medium so that it allows in micro liquid carriers to emerge from liquisolid particles along with drug molecules that will increase drug solubility in water if the non-volatile solvent used acts as a co-solvent (12).

3. There is an increase in the wetting process, and non-volatile solvents can act as surfactants and have a low surface tension so that the wetting of liquisolid primary particles can be increased. Wetting on the liquisolid technique can be seen by looking at the contact angle and increasing water demand (17). Liquisolid shows a lower contact angle compared to conventional tablets $(18,19)$.

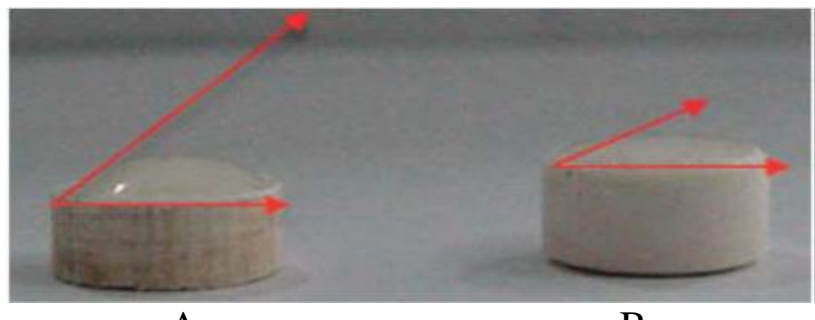

A

B

Figure 2. Depiction of the contact angle of a conventional and liquisolid tablets A

(Conventional Tablet) B (Liquisolid Tablet) (20).

\subsection{The Mechanism for the Release of Next Drugs from the Liquisolid Technique}

Replacing common hydrophilic carriers with hydrophobic carriers can cause low wetting, resulting in slow disintegration, and thus will expand drug release. It was observed that there were no changes in drug crystals or complex formation that occurred during the process of the liquisolid technique (12).

\subsection{Composition of Making Liquisolid Tablets}

Liquisolid contains active medicinal ingredients, fillers, coating materials, non-volatile solvents, and disintegrants

\section{Active ingredients}

The active ingredients used from BCS class II and IV were selected as potential drugs for the liquisolid system. Causes an increase in the solubility of the active ingredients, for example, prednisolone, hydrocortisone, carbamazepine, piroxicam, taxol, hydrochlorothiazide, griseofulvin, and furosemide (21).

\section{Filler material}

The filler material must have hydrophilic properties or excellent absorption properties and maintain compressibility properties, for example, avicel PH102 and lactose monohydrate (22).

\section{Coating Material}

The coating material is used to absorb excess liquid and produce free-flowing dry powder, for example, aerosil 200, cab-o-sil M5, and siloid (23).

\section{Non-volatile solvent}

The non-volatile solvent used should be inert, the viscosity is not too high, has a high boiling point, and has solubilization both for the drug used, for example, glycerin, polysorbate 80, propylene glycol, polyethylene glycol 200 and 400 (17).

\section{Disintegrant}

Disintegrants are agents that can enhance alkali, for example, SSG, cross-povidone, and sodium salt (24).

\subsection{Basis of Thought of Engineering Development in Liquisolid Technique}

Liquisolid technology develops and meets all the requirements needed to increase the solubility of drugs that are insoluble or have low solubility. The solubility mechanism is improved for drugs that are insoluble and will experience an increase in the wetting properties and reduce the surface tension between the release media. The tablet has also been developed to form the release of tablets slowly and show good results due to simplicity, effectiveness, and cost-feasibility of commercial feasibility with promising results that many researchers have done (34).

\subsection{Factors Affecting the Development of Liquisolid Technique}

Liquisolid technology structural components begin with the absorption or adsorption of liquid drugs or active ingredients with non-volatile solvents or into carrier materials. The role of solvents is to increase drug release quickly and 
make it easier to analyze release data obtained with a difference of weight in the nature and type of carrier used. All carrier materials used are porous, are highly hydrophilic and hygroscopic, with liquid drug principles. The first process will be absorbed to the surface with the presence of a

Table 1 Variation of various non-volatile solvents in the development of the liquisolid technique

\begin{tabular}{lll}
\hline No & Non-volatile Solvent & Reference \\
\hline 1 & Propylene Glycol & $(25)$ \\
2 & Poly (Ethylene glycol) 400 & $(26)$ \\
3 & Poly (Ethylene glycol) 300 & $(15)$ \\
4 & Poly (Ethylene glycol) 200 & $(27)$ \\
5 & Poly (Ethylene glycol) 600 & $(27)$ \\
6 & Glycerine & $(28)$ \\
7 & Polyoxy-35-castor oil & $(29)$ \\
8 & Poloxamer 181 & $(30)$ \\
9 & Propylene Glycol monocaprylate & $(31)$ \\
10 & Propylene Glycol dicaprylocaprate & $(26,31)$ \\
11 & Diethylene glycol monoethyl ester & $(31)$ \\
12 & Polysorbate 20 & $(32)$ \\
13 & Polysorbate 80 & $(25)$ \\
14 & Olive oil & $(26)$ \\
15 & Polyvinil Acetate & $(33)$ \\
\hline
\end{tabular}

mixed carrier material, and the absorption of liquid drugs absorbed through the pores can disintegrate the liquisolid formulation. Thus the dissolution process can be associated with the following mechanism:

1. Movement of release media through the carrier pores

2. Movement of release media by solubilization of the carrier material to the core

3. Release or diffusion or transfer of dissolved drug molecules in amounts (35).

\subsection{Characterization of Liquisolid Characterization of Physics Powder X-Ray Diffraction (PXRD)}

Liquisolid characterization can be predicted in several stages; first, knowing whether the mixture of liquisolid can have an amorphous form that can increase drug release. Second, determine the interaction of the active ingredients used with the addition of excipients (16). Liquisolid characterization includes physical characterization and physicochemical characterization. Liquisolid characterization uses diffraction powder x-ray.
Powder X-Ray Diffraction (PXRD) is used to measure diffraction patterns of crystalline materials. Each active ingredient will produce a specific pattern depending on the crystal lattice structure. Any polymorph, salt, or crystalline material will have a specific pattern. For this reason, PXRD inactive ingredients can be carried out in controlled environment conditions, using heat or controlled humidity environments to simulate Accelerated Predictive Stability (APS) conditions to assess the risk of conversion of any form, for example, Hydration or dehydration. Also, it can be used to determine whether there are crystal shape changes, for example, Hydration and disproportion of salt, in medicinal products that have occurred during the APS study. This depends on the presence of a diffraction peak, which can be detected both from the form of the active ingredient and the form that can be converted at the formulated level. Also, the peak of the active ingredient must be distinguishable from the peak of any crystalline excipient. PXRD can be used as a qualitative and quantitative assessment of the crystallinity level of pure active ingredients (36).

The results of the liquisolid PXRD formula changes between the active ingredients after the 
addition of excipients in the liquisolid technique, which decreases the degree of crystallinity, thus forming amorphous, the liquisolid formula can increase drug release (37).

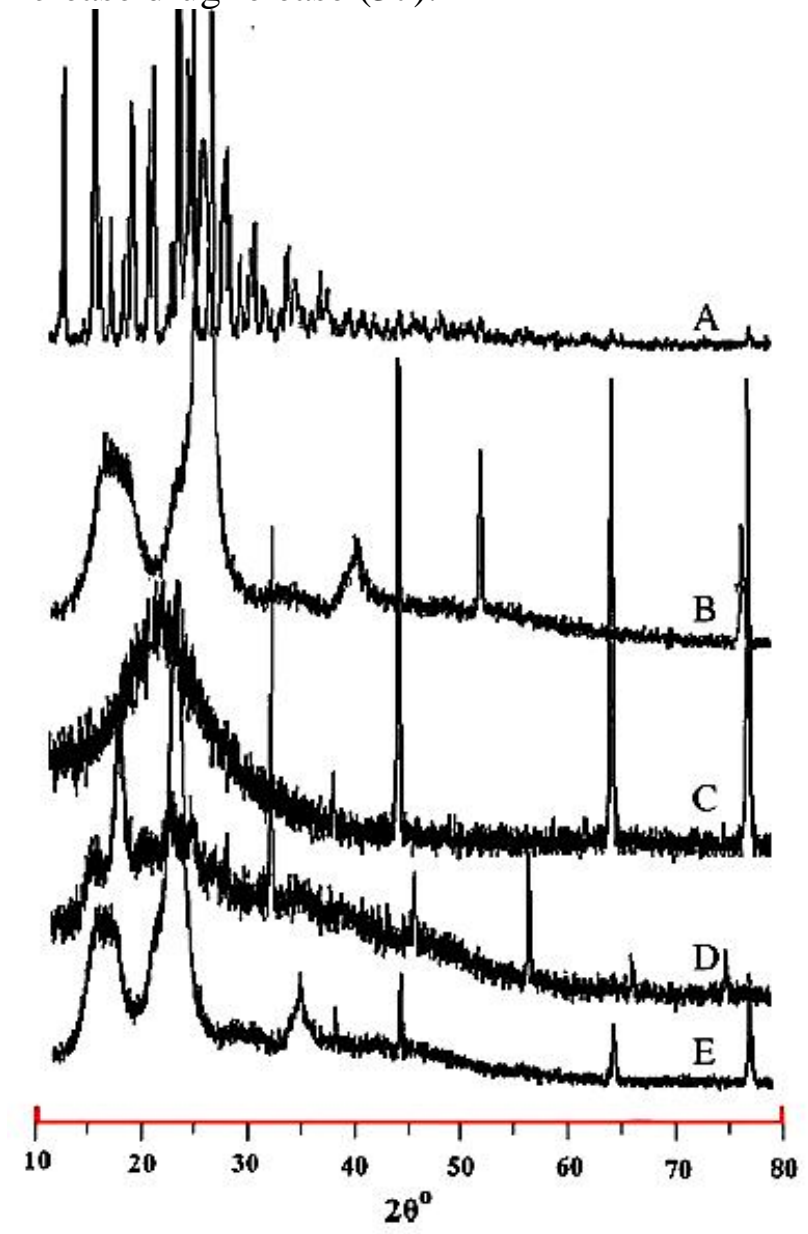

Figure 3. PXRD A) Pure Clonazepam B) MCC pH 102 C) Aerosil® 200 D) Sodium Starch Glycolate E) Clonazepam Optimization Liquisolid (37).

\section{Fourier Transform Infrared Spectroscopy (FTIR)}

Fourier Transform Infrared Spectroscopy (FTIR) is used to determine the shape of amino acid side chains, water molecules, and changes in group frequency vibration function (38). The results of FTIR in the liquisolid formula showed pure IR spectra of candesartan cilexetil (A) and liquisolid (B) formulas shown in Figure 4, show a special peak at $1080 \mathrm{~cm}-1$ due to smooth stretching relationships, $1752 \mathrm{~cm}-1$ because $-\mathrm{C}=$ $\mathrm{O}$ stretching ions carboxyl and at $1351 \mathrm{~cm}-1$ due to aromatic CN stretching occurs. The FTIR spectrum of liquisolid compacts was shown the same peak characteristics overriding the possibility of chemical interactions between drugs and excipients used in the formulation (39).

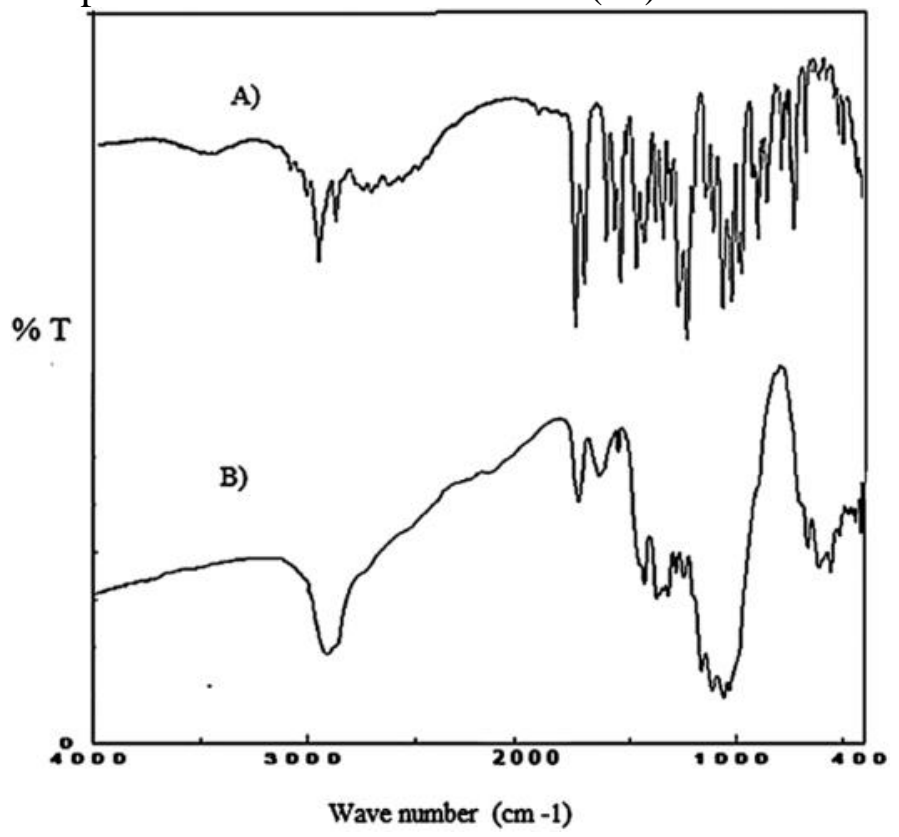

Figure 4. FTIR Spectrum (A) of Candesartan Cilexetil and (B) Liquisolid Formula (39).

\section{Differential Scanning Calorimetry (DSC)}

Differential Scanning Calorimetry (DSC) is a thermal technique where the difference in the amount of heat needed to increase the temperature of a sample is, for example, heat capacity material, measured as a function of temperature. In the context of APS, it is useful to detect phase transitions such as melting, glass transitions, and changes in the polymorph of active ingredients and excipients, and this transition can be detected as endothermic or exothermic peaks, or as a step in changing material heat capacity. The occurrence of thermal events such as these at temperatures in the experimental design of APS is an important warning for the behavior of non-representative inherent stability (36). The results of the DSC in the liquisolid formula with the ratio of pure active ingredients and other excipients showed that the liquisolid formula was not found in the crystalline form compared to the pure active ingredient (37).

\section{Scanning Electron Microscope (SEM)}

Scanning Electron Microscope (SEM) is used to determine the surface structure or morphology of a sample to produce a different form between the active material and the modified result. The results of the SEM in the liquisolid formula 
showed a change in the pure active ingredients with the results of the liquisolid formula, the results of the liquisolid formula of surface morphology were not found in crystalline form but rather in the form of amorphous (25).

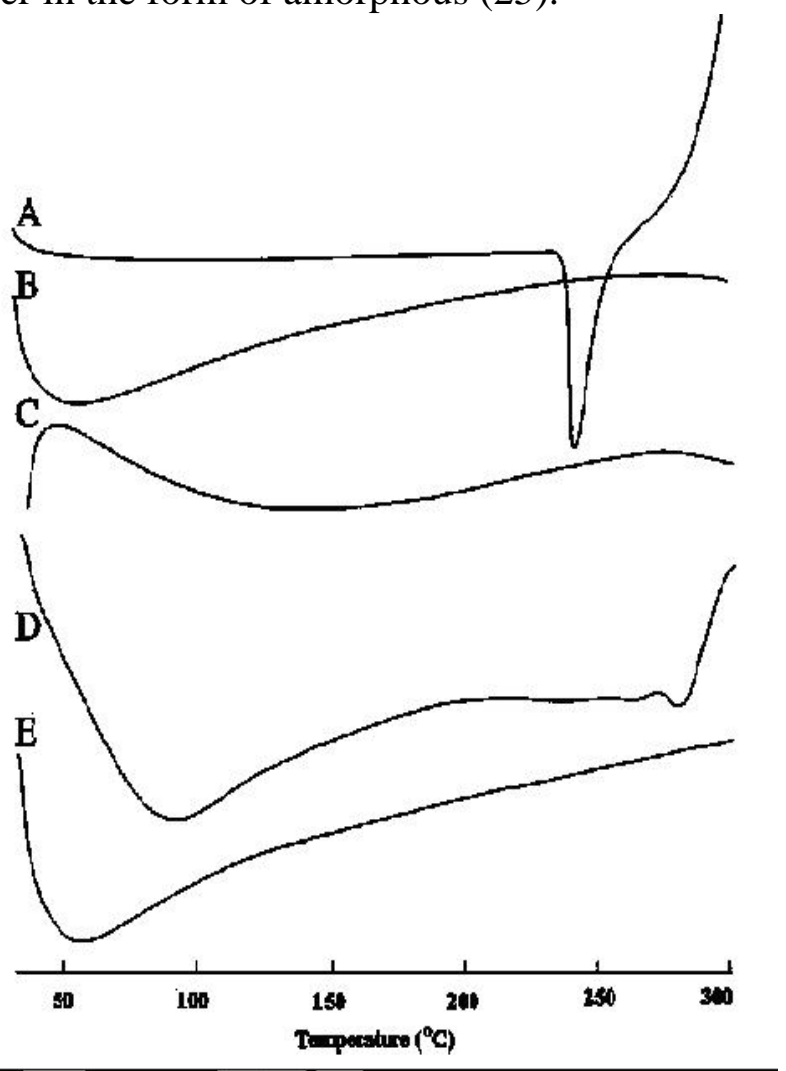

Figure 5. Thermograms DSC A) Pure

Clonazepam B) MCC pH 102 C) Aerosil@ 200 D)

Sodium Starch Glycolate E) Clonazepam

Liquisolid Optimization (37).

\section{Physicochemical Characterization}

\section{The Solubility of Liquisolid with Non-Volatile} Solvents

Solubility is the maximum amount of substance that can be completely dissolved in a certain amount of solvent, the solubility of a substance becomes very important in the pharmaceutical field because solubility is the main factor that can control the bioavailability of an active ingredient, provide information about the structure of drug substances and know the interactions between molecules (40). The methods used to improve the solubility of active ingredients that are difficult to dissolve in water include solid dispersion, nanoparticle technology, nanosuspension, nanoemulsion, microemulsion, cosolvent, particle size reduction, and cocrystals.
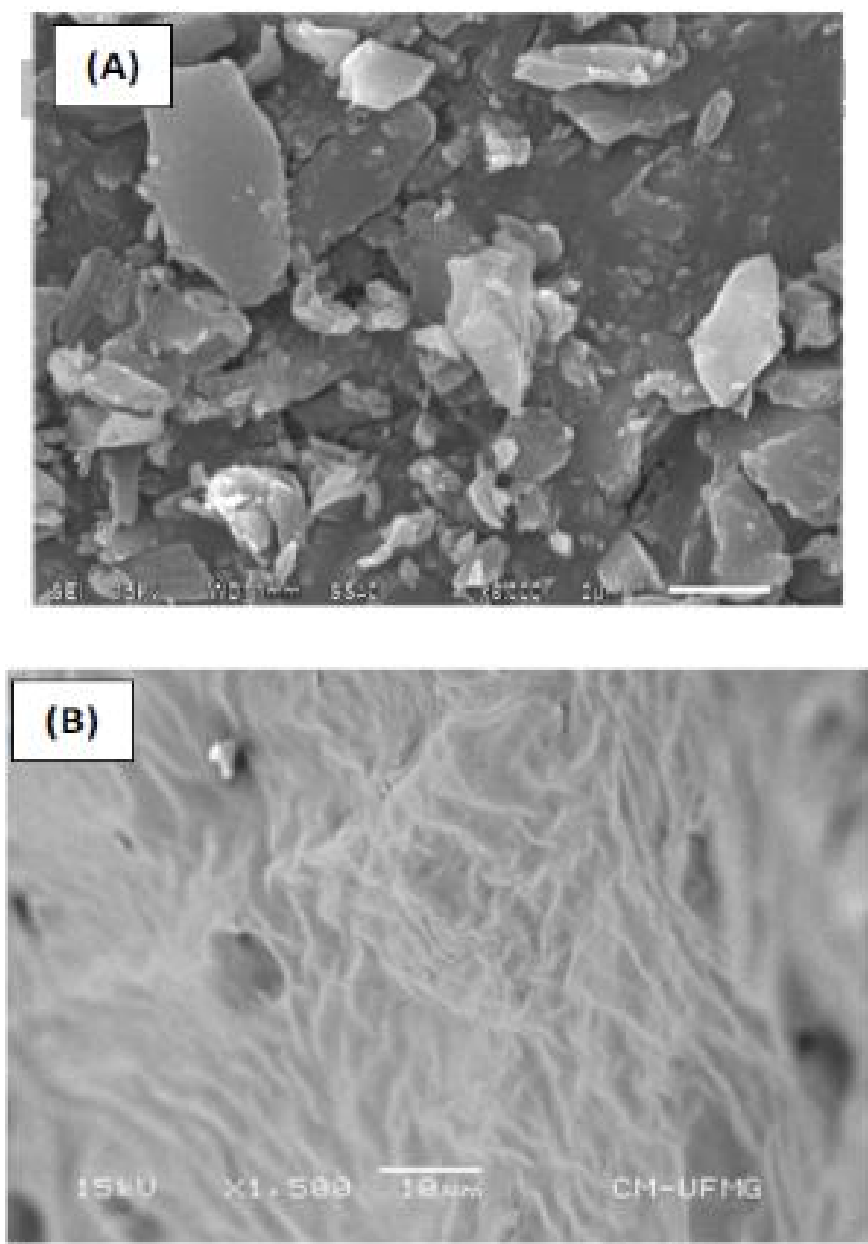

Figure 6. SEM (A) pure drug pioglitazone, (B) Optimized liquisolid formulation (25).

Based on table 2, it can be seen that the active ingredients used with non-volatile solvents can increase solubility up to $200 \mathrm{mg} / \mathrm{mL}$ in the active ingredient candesartan cilexetil using polysorbate 80 solvent. It could be said that with an increase in solubility using non-volatile solvents, several liquid carriers leave the liquisolid particles together with drug molecules, which will increase the solubility of the drug in water if the nonvolatile solvent used acts as a co-solvent (12). Non-volatile solvents must have a viscosity that is not too high, has a high boiling point, and has good solubilization (19). There is the wetting of non-volatile solvents that enter the particles of the active ingredient. 


\section{Release of Drug Liquisolid}

Drug release occurs when experiencing absorption after oral administration. Drug release after administration often becomes limited due to drug instability and low membrane permeability.
The rate of absorption of the drug depends on the physico-chemical properties of the drug, the addition of excipients, types of excipient, formulations and physiological conditions, and methods that can influence dissolution rates (43).

Table 2. The Comparison of solubility of liquisolid with non-volatile solvents

\begin{tabular}{|c|c|c|c|c|}
\hline No & $\begin{array}{c}\text { Active } \\
\text { ingredients }\end{array}$ & Solvent & $\begin{array}{l}\text { Solubility } \\
(\mathrm{mg} / \mathbf{m L})\end{array}$ & Reference \\
\hline 1 & Pioglitazone & PEG 400 & $83 \pm 2,29$ & $(25)$ \\
\hline 2 & $\begin{array}{l}\text { Azilsartan } \\
\text { medoxomil }\end{array}$ & Water & 78,85 & (26) \\
\hline 3 & Meloxicam & PEG 400 & 7,75 & (28) \\
\hline 4 & Griseofulvin & Cremophor®EL & 4,961 & (33) \\
\hline 5 & $\begin{array}{l}\text { Atorvastatin- } \\
\text { Glipizide }\end{array}$ & Propylene glycol & 92,87 & (41) \\
\hline 6 & Valsartan & Propylene glycol & 109,23 & $(27)$ \\
\hline 7 & Piroxicam & $\begin{array}{l}\text { Polysorbate } \\
80+\text { PEG } 400\end{array}$ & 21,73 & $(42)$ \\
\hline 8 & Clonazepam & Propylene glycol & 6,48 & (37) \\
\hline 9 & $\begin{array}{l}\text { Candesartan } \\
\text { cilexetil }\end{array}$ & Polysorbate 80 & 200,54 & (39) \\
\hline 10 & Naproxen & PEG 400 & 12,09 & $(30)$ \\
\hline
\end{tabular}

Table 3. The Comparison of the release of conventional drugs and liquisolid formulations

\begin{tabular}{|c|c|c|c|c|}
\hline \multirow{3}{*}{ No } & \multirow{3}{*}{$\begin{array}{c}\text { Active } \\
\text { Ingredients }\end{array}$} & \multicolumn{2}{|c|}{ Comparison of drug release } & \multirow{3}{*}{ Reference } \\
\hline & & Conventional & Liquisolid & \\
\hline & & Drug & Formulation & \\
\hline 1 & Candesartan & $35,81 \%$ & $90,60 \%$ & (39) \\
\hline 2 & Naproxen & $38,37 \%$ & $102,31 \%$ & $(30)$ \\
\hline 3 & Naproxen & $76,84 \%$ & $100,41 \%$ & (32) \\
\hline 4 & Griseofulvin & $37 \%$ & $95 \%$ & (15) \\
\hline 5 & Meloxicam & $78,88 \%$ & $107,36 \%$ & (28) \\
\hline \multirow[t]{2}{*}{6} & Furosemide & $45 \%(0,1 \mathrm{~N} \mathrm{HCl})$ & $67 \%(0,1 \mathrm{~N} \mathrm{HCl})$ & (44) \\
\hline & & $\begin{array}{l}80 \% \text { (Distilled } \\
\text { Water) }\end{array}$ & 92\% (Distilled Water) & \\
\hline
\end{tabular}

Based on table 3, it can be seen that the comparison of drug release between conventional drugs and liquisolid formula shows that the liquisolid formula has a high release percentage, this occurs because of the addition of constituent excipients and the addition of non-volatile solvents thereby reducing drug aggregation and increasing dissolution and occurring rates wetting process of non-volatile solvents which acts as a surfactant and has a small surface tension so that wetting of liquisolid particles can be increased. An increase in drug release can increase permeability in the membrane (22). With an increase in drug release, further testing of the physical and chemical stability of drugs is an important parameter. Stability is defined as the ability of the product to maintain within a specific time limit or time during the period of storage and use the same characteristics, and characteristics during the testing process (43). 


\section{Stability of Liquisolid Tablet Storage}

Factors affecting the stability of pharmaceutical products include the interaction of active and excipient ingredients, manufacturing processes, types of preparations, and loss of a percentage of drug release or activity from before. Drug stability testing methods include four stages, namely relative humidity stress, thermal stress, chemical stability, and solution stability. Testing relative humidity stress to determine the storage conditions is accelerated with moisture and used to determine the type of degradation product after storage (41).

Table 4. Stability for drug release

\begin{tabular}{cclcccc}
\hline No & $\begin{array}{c}\text { Active } \\
\text { Ingredients }\end{array}$ & Condition & \multicolumn{2}{c}{ Stability for drug release } & Reference \\
\hline 1 & Griseofulvin & $63 \%$ & $\begin{array}{c}\mathbf{4} \\
\text { weeks }\end{array}$ & $\begin{array}{c}\mathbf{3} \\
\text { Months }\end{array}$ & $\begin{array}{c}\mathbf{6} \\
\text { Months }\end{array}$ & \\
2 & $\begin{array}{c}\text { Atorvastatin- } \\
\text { Glipizide }\end{array}$ & $75 \%$ & - & - & - & $(33)$ \\
3 & Clonazepam & $75 \%$ & & $\checkmark$ & $\checkmark$ & $(41)$ \\
4 & Naproxen & $76 \%$ & $\checkmark$ & - & - & $(37)$ \\
\hline
\end{tabular}

Note: symbol $\checkmark$ indicates that there is no change after the resolution has been carried out against the shelf life (before and after) while the symbol - the researcher did not test at that time.

Based on table 4, it shows that with accelerated testing the dissolution test results do not show any changes after shelf life to a certain extent for liquisolid formula tablets and it can be said that the liquisolid technique is stable in a specific time (accelerated testing) (37). The liquisolid technique can change the physicochemical properties of an active ingredient, compared to pure active ingredients, the liquisolid technique is also a suitable method for improving the solubility of active ingredients that are not soluble in water and can improve its bio-availability.

Table 5. Competing Technologies with Liquisolid

\begin{tabular}{|c|c|c|c|}
\hline No & Technique & Mechanism & Reference \\
\hline 1 & Liquisolid & $\begin{array}{l}\text { Using non-volatile solvents, } \\
\text { lower cost, easy to formulate or } \\
\text { do, and high performance in drug } \\
\text { release (dissolution) and } \\
\text { bioavailability }\end{array}$ & $(45)$ \\
\hline 2 & Solid Dispersion & $\begin{array}{l}\text { Hydrophilic polymers or } \\
\text { solvent }\end{array}$ & (46) \\
\hline 3 & $\begin{array}{c}\text { Inclusion } \\
\text { complexation }\end{array}$ & $\begin{array}{l}\text { The stirring process is simple, } \\
\text { but it takes several hours and then } \\
\text { sophisticated screening, and } \\
\text { drying }\end{array}$ & $(46)$ \\
\hline 4 & $\begin{array}{l}\quad \text { Evaporative } \\
\text { precipitation into an } \\
\text { aqueous solution }\end{array}$ & $\begin{array}{l}\text { It produces smaller particle } \\
\text { size up to nanometers, but this } \\
\text { technique involves HPLC pumps } \\
\text { and heat exchangers }\end{array}$ & $(47)$ \\
\hline 5 & Micronization & $\begin{array}{l}\text { Using jet milling to reduce } \\
\text { particle size so that the surface } \\
\text { area increases }\end{array}$ & (48) \\
\hline 6 & Nano sizing & $\begin{array}{l}\text { Using ball milling to obtain } \\
\text { nanosized particles after spray } \\
\text { dried }\end{array}$ & $(48)$ \\
\hline
\end{tabular}




\section{Conclusion}

The liquisolid technique is one method to improve the solubility of active ingredients that are not soluble in water and can improve their bioavailability because of the increased drug release in the liquisolid method. There is an increase in surface area and wetting on drug particles, the advantages of the simple method, and cost-effective commercial feasibility with promising results in technology that many researchers have done. Formulations for making liquisolid tablets include the addition of nonvolatile solvents, fillers, drying agents, and disintegrant materials. Liquisolid characterized by specific instruments such as powder $\mathrm{x}$-ray diffraction (PXRD), Fourier transforms infrared spectroscopy (FTIR), differential scanning calorimetry (DSC), and scanning electron microscope (SEM). The liquisolid technique is proven and able to change the physicochemical properties of active pharmaceutical ingredients, especially the solubility, drug release, and stability of the liquisolid formula and also can be a solution for class II and IV BCS pharmaceutical active drug classes.

\section{Conflict of Interest}

The author here claims no involvement in a conflict of interest, financial or otherwise.

\section{References}

1. Ghadi R, Dand N. BCS class IV drugs: Highly notorious candidates for formulation development. J Control Release [Internet]. 2017;248:71-95. Available from: http://dx.doi.org/10.1016/j.jconrel.2017.01.01 4

2. Gad SC, Cassidy CD, Aubert N, Spainhour B, Robbe H. Nonclinical vehicle use in studies by multiple routes in multiple species. Int $\mathbf{J}$ Toxicol. 2006;25(6):499-521.

3. Strickley RG. Solubilizing excipients used in commercially available oral and injectable formulations. Pharm Res. 2004;21(2):201-30.

4. Barzegar-Jalali M, Dastmalchi S. Kinetic Analysis of Chlorpropamide Dissolution from Solid Dispersions. Drug Dev Ind Pharm. 2007;98(411):63-70.

5. Barzegar-Jalali M, Valizadeh H, Shadbad M-
RS, Adibkia K, Mohammadi G, Farahani A, et al. Cogrinding as an approach to enhance dissolution rate of a poorly water-soluble drug ( gliclazide ). Powder Technol [Internet]. 2010;197(3):150-8. Available from: http://dx.doi.org/10.1016/j.powtec.2009.09.00 8

6. Ma K, Wang N, Cheng L, Wei Y, Zhang J, Gao Y. Identification of novel adefovir dipivoxil-saccharin cocrystal polymorphs and their thermodynamic polymorphic transformations. Int $\mathrm{J}$ Pharm [Internet]. 2019;566(May):361-70. Available from: https://doi.org/10.1016/j.ijpharm.2019.05.071

7. Patel B, Shah C. Recent research on liquisolid technology for solubility enhancement-A review. Int J Adv Pharm. 2016;345-94.

8. Vasconcelos T, Sarmento B, Costa P. Solid dispersions as strategy to improve oral bioavailability of poor water soluble drugs. Drug Discov Today. 2007;12(23/24):1068-75.

9. Wang X, Michoel A, Den V, Mooter G. Solid state characteristics of ternary solid dispersions composed of PVP VA64, Myrj 52 and itraconazole. Int J Pharm. 2005;303(12):54-61.

10. Shah VP, Amidon GP. G.L. Amidon, H. Lennernas, V.P. Shah, and J.R. Crison. A Theoretical Basis for a Biopharmaceutic Drug Classification: The Correlation of In Vitro Drug Product Dissolution and In Vivo Bioavailability, Pharm Res 12, 413-420, 1995-Backstory of BCS [Internet]. Vol. 16, The AAPS Journal. 2014. Available from: http://link.springer.com/10.1208/s12248-0149620-9

11. El-Sayyad NME-M, Badawi A, Abdullah ME, Abdelmalak NS. Dissolution enhancement of leflunomide incorporating self emulsifying drug delivery systems and liquisolid concepts. Bull Fac Pharmacy, Cairo Univ [Internet]. 2017; Available from: http://dx.doi.org/10.1016/j.bfopcu.2017.02.00 1

12. Spireas. Liquisolid System and Methods of Preparing Same. United States Pat. 2002;1(12):1-9.

13. Khaled KA, Asiri YA, El-sayed YM. In vivo evaluation of hydrochlorothiazide liquisolid tablets in beagle dogs. Int $\mathrm{J}$ Pharm. 
2001;222:1-6.

14. Yadav VB, Yadav A V. Improvement of Solubility and Dissolution of Indomethacin by Liquisolid and Compaction Granulation Technique. J Pharm Sci Res. 2009;1(2):44-51.

15. Hentzschel C., Alnaief M, Smirnova I, Sakmann A, Leopold C. Enhancement of griseofulvin release from liquisolid compacts. Eur J Pharm Biopharm. 2012;80(1):130-5.

16. Sharma V, Pathak K. Attempts and outcomes of liquisolid technology: An updated chronological compilation of innovative ideas and adjuvants in the field. Pharm Biomed Res. 2016;2(15):1-21.

17. Javadzadeh Y, Siahi MR, Asnaashari S, Nokhodchi A. An investigation of physicochemical properties of piroxicam liquisolid compacts. Pharm Dev Technol. 2007;12(3):337-43.

18. Javadzadeh Y, Siahi-Shadbad M., BarzegarJalali, Nokhodchi A. Enhancement of dissolution rate of piroxicam using liquisolid compacts. Farm. 2005;60:361-5.

19. Javadzadeh Y, Jafari-navimipour B, Nokhodchi A. Liquisolid technique for dissolution rate enhancement of a high dose water-insoluble drug ( carbamazepine ). Int Jorunal Pharm. 2007;341:26-34.

20. Nokhodchi A, Hentzschel CM, Leopold CS. Drug Release From Liquisolid Systems: Speed it up, Slow it down. Int J Pharm Sci Nanotechnol [Internet]. 2010;3(1):795-802. Available from: http://www.tandfonline.com/doi/full/10.1517/ 17425247.2011.548801

21. Khan A, Agrawal S. Formulation and Evaluation of Lumefantrine Capsule Prepared by Using Liquisolid Technique. Int $\mathrm{J}$ Curr Pharm Res. 2018;10(2):43-50.

22. Savkare A, Bhavsar M, VD G, Kukar P. Liquisolid Technique: A Review. Int J Pharm Pharm Sci. 2017;8:68-75.

23. Kulkarni AS, Aloorkar NH, Mane MS, Gaja JB. Liquisolid Systems : A Review. Intertional J Pharm Sci Nanotechnol. 2010;3(1):795-802.

24. Sharma G, Khatry S, Arora S. Formulation and characterization of liquisolid compacts of valsartan. J Pharm Res. 2012;5(8):4158-62.

25. Bonthagarala B, Dasari V, KOtra V, Swain S, Beg S. Quality-by-Design based development and characterization of pioglitazone loaded liquisolid compact tablets with improved biopharmaceutical attributes [Internet]. Vol. 51, Journal of Drug Delivery Science and Technology. Elsevier B.V.; 2019. 345-355 p. Available from: https://doi.org/10.1016/j.jddst.2019.03.033

26. Chopra DK, Madhab DK, Sahu PK. Improvement of Oral Bioavailability of Azilsartan Medoxomil By Lipid Based Liquisolid Compacts: in Vitro and in Vivo Evaluation. Int Res J Pharm. 2019;9(12):1349.

27. Naveen C, Shastri N, Tadikonda RR. Use of the liquisolid compact technique for improvement of the dissolution rate of valsartan. Acta Pharm Sin B [Internet]. 2012;2(5):502-8. Available from: https://linkinghub.elsevier.com/retrieve/pii/S2 211383512001165

28. Dias RJ, Ranjan S, Mali KK, Ghorpade VS, Havaldar VD. Liquisolid Compacts of Meloxicam: in-vitro and in-vivo evaluation. Egypt Pharm J. 2018;190-200.

29. Yehia SA, El-Ridi MS, Tadros MI, El-Sherif NG. Enhancement of the oral bioavailability of fexofenadine hydrochloride via cremophor ${ }^{\circledR}$ el-based liquisolid tablets. Adv Pharm Bull [Internet]. 2015;5(4):569-81. Available from: http://dx.doi.org/10.15171/apb.2015.077

30. Tiong N, Elkordy AA. Effects of liquisolid formulations on dissolution of naproxen. Eur $\mathbf{J}$ Pharm Biopharm [Internet]. 2009;73(3):37384. Available from: http://dx.doi.org/10.1016/j.ejpb.2009.08.002

31. Komala DR, Janga KY, Jukanti R, Bandari S, Vijayagopal M. Competence of raloxifene hydrochloride loaded liquisolid compacts for improved dissolution and intestinal permeation. J Drug Deliv Sci Technol [Internet]. 2015;30:232-41. Available from: http://dx.doi.org/10.1016/j.jddst.2015.10.020

32. Nagabandi V, Tadikonda R, N. JK. Formulation Development and Evaluation of Liquisolid Systems To Improve the Dissolution Rate of Ketoprofen. Int J Biomed Res. 2012;2(10):3667-72.

33. Elkordy AA, Essa EA, Dhuppad S, Jammigumpula $P$. Liquisolid technique to 
enhance and to sustain griseofulvin dissolution: Effect of choice of non-volatile liquid vehicles. Int $\mathrm{J}$ Pharm [Internet]. 2012;434(1-2):122-32. Available from: http://dx.doi.org/10.1016/j.ijpharm.2012.05.07 2

34. Javadzadeh Y, Musaalrezaei L, Nokhodchi A. Liquisolid technique as a new approach to sustain propranolol hydrochloride release from tablet matrices. Int $\mathrm{J}$ Pharm. 2008;362:102-8.

35. Hassan M., El-saghir H. Enhancement of Dissolution and the Antiinflammatory Effect of Nimesulide, using Liquisolid Compact for Oral Application. Bull Pharm Sci,. 2011;34:18.

36. Scrivens G, Ticehurst M, Swanson JT. Strategies for Improving the Reliability of Accelerated Predictive Stability (APS) Studies [Internet]. Accelerated Predictive Stability. Elsevier Inc.; 2018. 175-206 p. Available from: http://dx.doi.org/10.1016/B978-0-12802786-8.00007-3

37. Sanka K, Poienti S, Mohd AB, Diwan P V. Improved oral delivery of clonazepam through liquisolid powder compact formulations: Invitro and ex-vivo characterization. Powder Technol [Internet]. 2014;256:336-44. Available from: http://dx.doi.org/10.1016/j.powtec.2014.02.02 6

38. Berthomieu C, Heinerwadel R. Fourier transform infrared ( FTIR ) spectroscopy. Photosynth Res. 2009;101:157-70.

39. Sayyad FJ, Tulsankar SL, Kolap UB. Design and development of liquisolid compact of candesartan cilexetil to enhance dissolution. $\mathbf{J}$ Pharm Res [Internet]. 2013 May;7(5):381-8. Available

from: http://dx.doi.org/10.1016/j.jopr.2013.05.012

40. Gong Y, Grant DJW, Brittain HG. Principles of Solubility. 1995;

41. Muthyala J, Singh SK, Gulati M, Kumar B, Rathee H, Ghai D, et al. Systematic development and characterization of liquisolid compacts of atorvastatin-glipizide binary mixture to achieve enhanced dissolution and stability profile. Asian J Pharm. 2016;10(4).

42. Harsha INS, Lohithasu D, Babu KM, Madhu G, Lavanya K, Swaroop KK. Formulation and Characterization of Piroxicam Liquisolid Technique for Solubility Enhancement. 2014;3(3):1393-404.

43. Reddy KV, Reddy D., Shruti P. Principles of Drug Release In Various Dosage Forms. World J Pharm Res. 2015;3(April):4.

44. Akinlade B, Elkordy AA, Essa EA, Elhagar S. Liquisolid systems to improve the dissolution of Furosemide. Sci Pharm. 2010;78(2):32544.

45. Srinivas L, Kumar V, Ramya P, Manasa P. Preparation and biopharmaceutical evaluation of piroxicam liquisolid system. INDO Am J Pharm Sci. 2014;

46. Jain R, Brito L, Straub J. Effect of powder processing on perfomance of Fenofibrate formulations. Eur J Biopharm. 2008;69(34):727.

47. Huang Q, Wang J, Zang Z-B. Preparation of ultrafine Fenofibrate powder by solidification process from emulsion. Int $\mathrm{J}$ Pharm. 2008;368:160-4.

48. Vogt M, Kunath K, Dressman J. Dissolution enhancement of Fenofibrate by micronization, co-grinding and spray-drying comparison with commercial preparations. Eur J Pharm Biopharm. 2008;68:283-8. 